\title{
CONFLITO E MOVIMENTOS SOCIAIS NO ACIONALISMO DE ALAIN TOURAINE
}

\section{Angelina Peralva}

é pesquisadora associada ao Centre d'Analyse et d'Intervention Sociologiques (Cadis) na École des Hautes Études en Sciences Sociales. Paris, França. E-mail: <peralva@univ-tlse2.fr>

Orcid: 0000-0003-0479-4402

http://dx.doi.org/10.1590/0102-160194/106

\section{Introdução}

Antes de se tornar sociólogo, Alain Touraine foi o que se chamou mais tarde um "établi": ${ }^{1}$ alguém que, vindo de outro meio social, incorporou-se ao mundo dos trabalhadores. Jovem, Touraine trabalhou por um ano nas minas de carvão do norte da França, na região de Valenciennes. Toda a sua sociologia da ação é, de início, marcada pela imagem do movimento operário. Isso é dito por ele, em um livro de entrevistas autobiográficas:

Para mim, jovem burguês hiper escolarizado, a Liberação e o período 1945/47 (os comunistas no governo) mudaram tudo. Mas a irrupção da classe operária em minha experiência de vida, como realidade e como força, foi mais concretamente importante. Se alguém me pedisse para desenhar a sociedade, haveria no seu centro uma fábrica ou uma mina. Para mim, o mundo operário era o fogo (e

\footnotetext{
1 A expressão designa militantes de classe média que, nos anos 1960, se empregavam nas fábricas para se aproximar do mundo operário. Robert Linhart (1978) fez dela o título de um livro onde relata sua experiência de um ano como operário numa fábrica de automóveis da Citroën em Paris.
} 
eu nunca perdi essa imagem que hoje se tornou arcaica). Escolhi a mina porque o carvão chama o fogo. (Touraine, 1977, p. 45$)^{2}$

Essa sociologia mudou muito ao longo do tempo, a tal ponto que é possível falar de três "Touraine", relativamente diferentes um do outro, não obstante o fato de que fortes elementos de continuidade caracterizam também seu pensamento.

As primeiras pesquisas sobre o trabalho operário conduziram a uma noção central do acionalismo tourainiano: a noção de consciência operária. Apresentada como o resultado de uma ampla pesquisa empírica (Touraine, 1966), ela está por trás de uma primeira construção teórica mais geral (Touraine, 1965) e permanece um elemento central, quase dez anos mais tarde, em Production de la société (1973). Este último livro foi concebido como um ponto de partida, um arcabouço teórico capaz de abrir caminho para um conjunto de pesquisas empíricas. Mas ele é, ao mesmo tempo, um livro de transição. De um lado, toda a construção de uma sociologia da ação ali proposta toma por base o modelo do movimento operário; ao mesmo tempo, o livro é fortemente alimentado por um debate em torno da sociedade pós-industrial e desse formidável terremoto que foi, no século XX, a luta estudantil dos anos 1960 .

De tal modo que, se Production de la société, construção analítica extremamente abstrata, só é possível porque a ideia de consciência operária e de movimento operário estavam no centro de uma análise da sociedade industrial, o livro tem os olhos voltados para o futuro. E é isso que permite a Touraine, já naquele momento, definir ali a grande questão que dominaria nosso presente como sendo a busca dos atores, dos campos de ação e do que estaria em jogo nos

2 Todas as traduções são da autora do artigo. 
combates sociais das sociedades pós-industriais. Construído a partir das conquistas teóricas do primeiro Touraine, Production de la société já anuncia um segundo.

Trata-se do Touraine dos "novos movimentos sociais". Em meados dos anos 1970, para levar a cabo essa busca dos atores, dos campos de ação e do que estaria em jogo na sociedade pós-industrial, foi inventado o método da intervenção sociológica. Todo um programa de investigação de diferentes lutas - estudantis, feministas, ambientalistas, regionalistas e operárias - foi organizado (Touraine et al., 1978, 1980, 1981, 1982, 1984). ${ }^{3}$ Mas, em fins dos anos 1980, registram-se, em conferências e nos debates internos do Centre d'Analyse et d'Intervention Sociologiques (Cadis), os primeiros sinais de uma nova mudança de orientação.

É difícil saber exatamente quando termina o segundo Touraine. Ao que tudo indica, paralelamente às pesquisas citadas, uma nova problemática estava em gestação, a do 162 sujeito pessoal - por oposição ao sujeito histórico que foi o movimento operário. Em todo caso, o livro que marcou a ruptura foi sem dúvida Critique de la modernité (Touraine, 1992). ${ }^{4}$ Mais difícil ainda é dizer o que foi guardado e o que foi abandonado entre o iníco e o fim desse percurso. A noção de conflito foi formalmente mantida, mas perdeu substância, ainda que em vias de recuperação num período mais recente. A noção de movimento social desapareceu, cedendo lugar à noção de movimento cultural, pouco teorizada. Isso se explica pela ideia de tipos societais e das mutações que conduziriam de um tipo a outro, as sociedades industrial e pós-industrial configurando tipos distintos.

\footnotetext{
3 Sobre o movimento feminista, apenas um relatório foi produzido.

4 Em 1987 e 1988, após uma longa estada no Chile, Touraine lança, primeiro em espanhol, depois em francês, dois livros sobre a América Latina. Depois disso, nenhum livro foi publicado até 1992. Um intervalo notável para alguém habituado a publicar um livro por ano ou, no máximo, de dois em dois anos.
} 


\section{Conflito e movimentos sociais no acionalismo tourainiano}

Apresentaremos a seguir as principais categorias analíticas que marcaram essa evolução do acionalismo tourainiano, introduzindo mais adiante algumas questões quanto à utilidade de um eventual retorno ao aparelho conceitual inicial para entender acontecimentos recentes que pontuaram a história brasileira.

\section{A noção de historicidade}

A carreira de Touraine iniciou-se em um momento fortemente marcado pelo funcionalismo de Talcott Parsons. O encontro dos dois ocorreu em Harvard, em 1952, onde Touraine viveu um ano com uma bolsa da Fundação Rockefeller. A noção de historicidade pautou a ruptura com o funcionalismo parsoniano, através da afirmação da insuficiência de uma imagem da sociedade que se limitaria a uma pura lógica de reprodução. Por oposição a essa imagem, Touraine afirmava que a sociedade não apenas se reproduzia, ela também se produzia. Ela não era o que era, mas o que se fazia ser, através de uma dinâmica de acumulação, capaz de retirar da produção social um excedente destinado ao investimento; através do conhecimento - capacidade de simbolização própria às coletividades humanas e elemento de sua transformação; e através de um modelo cultural que definiria os quadros gerais de funcionamento de diferentes tipos de sociedade. A historicidade designa portanto, para Touraine, não o caráter histórico da vida social, mas esse traço particular das coletividades humanas que é a capacidade de que dispõem para agir sobre si mesmas - traço que impediria, segundo ele, qualquer analogia com organismos que desenvolvam funções puramente adaptativas.

\section{A noção de consciência operária}

$\mathrm{O}$ grande ganho das primeiras investigações de Touraine foi o de afirmar a existência de uma consciência 
de classe dos operários, suscetível de ser empiricamente verificada, e muito concretamente situada, no interior das relações de trabalho. Uma ampla pesquisa por questionário realizada com operários situados em diferentes estágios do processo de passagem entre o sistema profissional e o sistema técnico de trabalho, entre o puro ofício e a automação avançada, permitiu-lhe estabelecer que o máximo de consciência de classe encontrava-se a meio caminho entre essas duas situações extremas, quando a autonomia profissional do operário enfrenta as obrigações impostas pelo sistema de organização do trabalho (Touraine, 1966, p. 50).

Por trás dessa afirmação, um pressuposto: enquanto a condição operária foi globalmente definida pela miséria e pela proletarização, as atitudes operárias só poderiam orientar-se para a revolta e a revolução, definindo-se por uma consciência proletária, de privação e ruptura. Foi a melhoria das condições gerais de vida dos operários que tornou perceptível a existência de 164 uma referência positiva ao trabalho. As relações de trabalho são portanto o lócus da consciência operária, que Touraine define, nessa mesma ocasião, como um sistema de exigências que deriva do próprio trabalho, através da dupla valorização da criatividade e do controle do trabalhador sobre suas obras. A consciência de classe não se define portanto somente como uma consciência de pertencimento, ou como sentimento de hostilidade em relação a uma outra categoria sócio-econômica; define-se mais precisamente como identificação entre um conflito vivido e um princípio de explicação social e histórico. Essa consciência é o que define o operário enquanto sujeito histórico. A noção de consciência operária está por trás da concepção tourainiana de movimento social, definido como conduta coletiva orientada para a historicidade e portadora de um conflito de classes.

\section{A sociedade como sistema de sistemas de ação}

Da noção de produção da sociedade, que dá título ao livro de mesmo nome (Touraine, 1973), derivam relações 
de classes: uma classe popular se opõe a uma classe superior pelo controle da historicidade. Exatamente porque a sociedade se produz, e não apenas se reproduz, sua divisão em classes aparece como algo inelutável. A classe superior se apropria da historicidade, afirmando sua dominação sobre a classe popular. Nesse sentido, a historicidade é uma referência comum positiva para ambas as classes: a historicidade é o que está em jogo nos conflitos de classes. Tais conflitos se expressam através de movimentos sociais, categoria de análise da ação social. Qualquer mobilização coletiva, mesmo de base popular, não é um movimento social. Só o é quando visa a historicidade, constituindo-se assim como expressão de um conflito de classes.

Essa distinção remete a um último elemento geral do acionalismo tourainiano, presente no Touraine da primeira e da segunda fase: sua concepção da sociedade como um "sistema de sistemas de ação", relativamente autônomos mas ao mesmo tempo hierarquizados. Isso lhe permite distinguir diferentes ordens de significados das condutas humanas. Na perspectiva parsoniana, as condutas definem-se fundamentalmente em termos de conformidade ou desvio relativamente a normas e valores coletivos (Parsons, 1951). Para o individualismo metodológico - na sociologia francesa, Boudon é uma referência incontornável (Boudon, 1977, 1979) - ou para a teoria da ação organizada (Crozier e Friedberg, 1977), essas condutas têm um significado principalmente estratégico. Touraine acrescenta um terceiro tipo de conduta: a conduta de historicidade, expressão de um conflito social geral - conduta do tipo movimento social.

A cada sistema de ação, corresponde assim, na perspectiva tourainiana (Touraine, 1973), um tipo particular de conduta coletiva. No nível mais elevado, encontra-se o sistema de ação histórica, que organiza as relações entre o funcionamento da sociedade e sua historicidade. Por seu intermédio, as orientações da historicidade transformam-se 
em categorias da prática social; e, inversamente, recursos materiais e simbólicos são mobilizados na ação da sociedade sobre si mesma. Em nível intermediário, situa-se o sistema institucional. Ele é o lócus da produção de decisões e de normas. Nesse nível que diferentes atores definem as regras do jogo social. Por seu intermédio, as orientações da historicidade traduzem-se em normas que regulam a prática social. No nível mais baixo, enfim, situa-se o sistema organizacional. É ali que se manifestam da maneira mais direta as práticas sociais. É ali também que os três níveis de ação a que nos referimos aparecem amalgamados.

O objeto próprio de uma sociologia da ação, na acepção tourainiana daquele momento, consistia em separar no plano analítico, no interior das condutas coletivas, orientações referentes a cada um desses níveis de ação. A cada sistema de ação corresponderia, assim, conforme dissemos, um tipo particular de conduta coletiva: ao sistema de ação 166 histórica e às relações de classes, os movimentos sociais; ao sistema institucional, as condutas estratégicas, as lutas de influência e as tensões institucionais; e ao sistema organizacional, os jogos entre papéis desempenhados, as expectativas face a esses papéis e as condutas de crise organizacional.

Isso significa que toda ação coletiva poderia ser entendida como potencialmente analisável a partir de cada um desses tipos de condutas. Uma luta poderia ser a expressão principal de uma crise organizacional; de uma tensão institucional; ou de uma relação conflitiva no plano da historicidade - em outros termos, como um movimento social. $\mathrm{O}$ método da intervenção sociológica, cujos princípios foram expostos em La voix et le regard (Touraine, 1978), foi inventado para descobrir que orientação das condutas tinha maior peso na ação coletiva, mas sobretudo para esclarecer seu significado enquanto movimento social.

Uma última observação sobre esse tema. Para Boudon (1977, 1979), que ancora, como Mancur Olson (1978), a 
ação individual na noção de interesse, a passagem da ação individual para a ação coletiva é algo problemático e a noção de efeito perverso insiste na possível dissociação entre uma e outra. Para Crozier e Friedberg (1977), a cooperação constitui uma preocupação central - ela deriva quase que naturalmente do jogo estratégico dos atores. A cooperação impõe limites a esse jogo estratégico, é um imperativo da ação. Ação individual e ação coletiva formam portanto dois aspectos complementares do mesmo problema. Em sua análise dos movimentos sociais, Touraine situa-se diretamente no plano das ações coletivas. O conflito em jogo nos movimentos sociais mantém-se, no entanto, acima de tudo, como um conflito individual. No caso do movimento operário, ele se baseia na relação, pessoal e direta, entre o operário e seu trabalho, ou suas obras. A passagem da consciência individual à consciência coletiva se opera por meio da implicação em uma experiência comum.

\section{Mutação societal e sujeito pessoal}

A noção de mutação societal é construída para sinalizar a passagem entre dois sistemas de ação histórica, ou dos tipos de sociedade; a noção de sujeito pessoal, por sua vez, emerge com força a partir do momento em que a ideia de sociedade pós-industrial, através da qual Touraine inicialmente pensou o declínio da sociedade industrial, perde também sua força analítica.

\section{A sociedade pós-industrial e os novos movimentos sociais}

Em 1969, Touraine formalizou uma ideia que iria ocupar um lugar importante na sua reflexão: a ideia de mutação societal. Essa noção, que ocupa um lugar específico em sua análise dos processos de mudança, foi mais sistematicamente abordada em Production de la société (1973). Ela designa a transição entre dois sistemas de ação histórica, sem que sejam levados em conta os mecanismos concretos através dos quais a mudança ocorre. Através da noção de mutação, 
trata-se simplesmente de descrever tipos de sociedades que se distinguem pela maneira de operar sua historicidade.

Ao publicar La société post-industrielle (1969), Touraine sustentou justamente que estava em curso uma verdadeira mutação societal. A sociedade industrial, que havia gestado o movimento operário, encontrava-se em declínio, ao passo que emergia uma outra, que se poderia também chamar programada. Enquanto a sociedade industrial havia atribuído um lugar central ao maquinismo e ao trabalho, a sociedade pós-industrial era dominada pelos grandes aparelhos de produção do conhecimento e pela indústria cultural. A tecnocracia estava destinada a substituir o antigo patronato, dirigindo os processos de mudança, mas também ampliando o campo da dominação, que passava a integrar fabricação, informação, formação e consumo mais estreitamente que antes.

Essa nova representação da vida social deu origem, conforme indicamos, a um vasto programa de pesquisas desen168 volvido ao longo dos anos 1970 e 1980, orientado para a análise das lutas que se supunha portadoras de novos movimentos sociais. Estes últimos estariam fadados a ocupar, na sociedade pós-industrial nascente, o lugar ocupado, na sociedade industrial, pelo movimento operário. Qualquer que tenha sido a importância desse programa de pesquisas do ponto de vista dos conhecimentos produzidos sobre os atores em evolução na sociedade francesa da época, no que se refere à hipótese em que ele se baseava seus resultados se revelaram claramente negativos.

Touraine havia definido os movimentos sociais, à imagem do movimento operário, através de três princípios: um princípio de identidade, entendido como capacidade de um ator coletivo definir-se a si mesmo enquanto ator; um princípio de oposição, entendido como capacidade de definir seu adversário; e um princípio de totalidade, correspondendo ao que de comum estaria em jogo na luta. O movimento operário definiria sua própria identidade através da relação 
positiva do trabalhador às suas obras, ao mesmo tempo enquanto base de sua criatividade e fonte de progresso social. ${ }^{5}$ Opunha-se ao patronato, resistindo à dominação sofrida. E ambos - patrão e operário - identificavam-se ao progresso social e científico, objeto de suas lutas e jamais redutível nem a um, nem a outro.

O fracasso do programa de pesquisas sobre os novos movimentos sociais vem do fato de que - salvo no caso excepcional do estudo sobre o sindicato Solidariedade na Polônia (Touraine et al., 1982), que revelou-se como a combinação entre uma luta sindical, um movimento democrático e um movimento de libertação nacional - o modelo acima descrito não encontrou correspondência nas lutas empíricas estudadas. Em nenhum caso os atores coletivos analisados puderam designar a tecnocracia como figura geral de um adversário da luta e nenhum princípio de totalidade, nenhuma referência compartilhada entre dominantes e dominados no interior do movimento puderam tampouco ser enunciados.

Face a tais resultados, duas hipóteses pareceriam cabíveis. A primeira, de tipo histórico: em caso de uma mutação incompleta, a sociedade nascente não teria ainda produzido seus novos atores centrais. A segunda, de tipo teórico: o modelo imaginado a partir do exemplo do movimento operário não se aplicaria à sociedade programada. Tudo faz crer que Touraine optou pela segunda hipótese. Em todo caso, à exceção de um programa de pesquisas sobre o antigo mundo socialista, que ele dirigiu quase que apenas por delegação e do qual nenhum livro de sua autoria foi publicado, desde o começo dos anos 1990 Touraine deixou de lado suas pesquisas empíricas para dedicar-se quase que

\footnotetext{
${ }^{5}$ O poema "O operário em construção", de Vinicius de Moraes (1959) é uma tradução poética perfeita dessa concepção tourainiana. Vinicius diz do operário: "era ele que erguia casas/ onde antes só havia chão" (Moraes, 1959, p. 45). Erguer casas é um ato de criação de significado simultaneamente individual e coletivo.
} 
com exclusividade a um longo retorno à teoria - retorno de que abordaremos agora alguns aspectos.

\section{O tema do sujeito pessoal}

Essa inflexão implicou um abandono dos quadros habituais da reflexão sociológica, em prol de uma incursão mais geral na história do pensamento moderno. De início, o debate versou sobre a pós-modernidade e a condição pós-moderna. Na França, naquele momento, o interlocutor a quem Touraine procurou responder foi Jean-François Lyotard (1979). Lyotard havia pautado a questão do declínio das grandes narrativas, expressão da razão moderna, que haviam mobilizado os seres humanos em torno de uma promessa de futuro: fé no progresso, na justiça, na busca de uma sociedade melhor, no socialismo. O fim das grandes narrativas instalava a humanidade em uma experiência fragmentária e vazia de sentido, projetando-a num além da

170 modernidade, a pós-modernidade.

Critique de la modernité (1992), de certo modo, é a resposta proposta por Touraine a esse debate. Mas o livro lhe permite ao mesmo tempo empreender uma revisão geral de sua própria teoria da ação. São três partes. A primeira chama-se "A modernidade triunfante" e mostra como a experiência histórica da modernidade foi efetivamente vivida no Ocidente como uma afirmação forte da razão, em ruptura com preconceitos e crenças de um mundo tradicional. A razão é evocada com duas acepções principais: a partir de seu impacto sobre a transformação das relações entre o homem e o meio - a razão instrumental; mas também a partir de seu impacto sobre a transformação das relações entre os homens - a racionalidade normativa, que implicava, mais além de qualquer fundamento divino, a capacidade de a humanidade fabricar uma ordem propriamente humana.

A segunda parte do livro chama-se "A modernidade em crise". Ali, Touraine mostra o esgotamento progressivo de 
uma modernidade pautada em um ideal de correspondência estreita entre o ator e o sistema, concepção que reduzia o ator à interiorização de uma racionalidade normativa de valor universal. Esse esgotamento teria duas origens: a autonomização crescente do ator que afirmaria cada vez mais fortemente sua liberdade; e a crítica empreendida por intelectuais anti-modernos contra uma razão percebida como dominação, e portanto desqualificada em suas pretensões à universalidade.

Na terceira parte, enfim, Touraine apresenta sua própria concepção da modernidade. Não basta, diz ele, concebê-la em termos puramente negativos, como recusa da tradição e afirmação radical do valor universal da razão. Desde o início, enquanto experiência, a modernidade foi informada por duas lógicas complementares, mas opostas: uma lógica de racionalização - incidindo ao mesmo tempo no plano instrumental e no plano normativo, conforme evocamos anteriormente; e uma lógica de subjetivação - pautada pela referência do sujeito a um princípio não social de autonomia e liberdade: vontade de ser ator de sua vida, vontade de ser sujeito, de ser capaz de dizer eu. Tal sujeito, agora definido por Touraine em termos não sociais, constitui-se e ganha forma na luta contra o antissujeito - isto é, contra tudo aquilo contra o qual um sujeito se insurge pelo fato de ver-se impedido de ser sujeito. O sujeito tourainiano é sempre um dissidente: "É o gesto de recusa, de resistência que cria o sujeito" (Touraine, 1992, p. 318).

A partir dessa representação extremamente geral da experiência moderna como tensão entre a racionalização e a subjetivação, um novo retorno sobre a análise de sociedades concretas se tornava possível. A constatação de um debilitamento da razão moderna em sua expressão normativa permitia compreender melhor por que os movimentos da sociedade programada não podiam repetir a configuração própria do movimento operário enquanto expressão interna a uma estrutura classista. Touraine havia concebido 
a classe superior como duplamente identificada a uma lógica de ordem (ou de dominação) e a uma lógica de mudança (ou de racionalidade instrumental). A razão moderna, doravante menos ambiciosa, passara a ancorar-se cada vez mais em dinâmicas sistêmicas, definidas por suas próprias determinações, mas abandonando qualquer ideia de uma ordem social. O poder se exerceria por identificação direta à dinâmica econômica e aos processos de mudança, adotando preferencialmente formas derivadas de exercício da dominação.

Daí por que o fato importante passava a ser a separação entre o sujeito e o sistema, este último sendo definido como um campo de produção econômica e cultural, com impacto direto sobre o desenvolvimento. Touraine dirá por conseguinte:

O mais visível é a dissociação entre a ordem da mudança e a ordem do ser, antes associados na ideia de modernidade, que significava ao mesmo tempo racionalidade e individualismo. Cresce a distância entre as mudanças incessantes no plano da produção e do consumo e o reconhecimento de uma personalidade individual, que é ao mesmo tempo sexualidade e identidade cultural coletiva. (Touraine, 1992, p. 119)

Isso implicava também o reconhecimento de que, sem desaparecer, a dominação tornava-se menos direta e visível. Sua visibilidade passava a depender de um conflito explicitado pelo sujeito pessoal e pelos movimentos sociais. $\mathrm{Na}$ sociedade pós-industrial, ou programada, "o antissujeito" (nova figura da dominação) manifestava-se através de lógicas de aparelho, notadamente nas indústrias culturais, mas só o conflito seria capaz de torná-lo identificável.

Embora expressando-se em termos diferentes, Touraine manteve uma linha de continuidade com seu pensamento anterior, em função do lugar fundamental atribuído ao conflito enquanto expressão de uma oposição geral entre um 
princípio de ordem/dominação, mas também de modernização e mudança próprios à razão moderna, e um princípio de resistência e liberdade manifestado através do sujeito. O movimento operário foi uma das figuras históricas mais importantes desse conflito, expresso na tensão entre racionalização e subjetivação.

A pesquisa sobre os novos movimentos sociais representou um esforço para identificar esse conflito no interior dos quadros culturais que modelavam a experiência e a contestação estudantil e do movimento de mulheres, a identidade regional face à identidade nacional no caso do movimento occitano, o apelo a relações de equilíbrio entre o homem e a natureza por oposição às lógicas puramente tecnocráticas no caso do movimento ecologista nascente. Esse esforço, conforme dissemos, fracassou certamente por duas razões principais. De um lado esses movimentos, por mais novos que fossem, emergiam envoltos nos trajes do movimento operário. Usavam sua linguagem e queriam desenvolver-se à sua sombra. Era-lhes muito difícil, por conseguinte, conceber a si próprios como movimentos distintos e autônomos. Mas, por outro lado, a própria teoria encontrava-se atrasada em relação à realidade dessas novas mobilizações, na medida em que se agarrava a uma definição do conflito social formulada em termos muito diretamente classistas - com a ideia de que uma tecnocracia viria substituir o antigo patronato e com definições da dominação que, embora não fossem as mesmas observadas no quadro da sociedade industrial, permaneciam formalmente análogas ou de mesma natureza.

A hipótese enunciada em Critique de la modernité (Touraine, 1992) de um adversário diretamente estruturado pelo conflito, pelo movimento e pela ação coletiva (e não mais imediatamente identificável por sua posição nas relações de trabalho, como fora o patronato frente ao movimento operário), foi ilustrada em um dos livros posteriores de Touraine (1999), pela referência aos "novos novos 
movimentos sociais" ou movimentos dos "sem": sem papéis, desempregados, população de rua... Touraine sugeria que, na conflitualização da experiência da exclusão - ela própria, um dos sinais mais notáveis de uma separação patológica entre o sujeito e o sistema -, era possível vislumbrar essa capacidade dos movimentos sociais de estruturarem a dominação, ao mesmo tempo em que a combatiam.

Mas outra diferença importante separa o movimento operário enquanto figura histórica do conflito moderno e esses "novos novos" movimentos emergentes, no quadro da sociedade programada. O objeto do conflito que opunha operários e patrões era a dupla identificação de uns e outros com o progresso enquanto expressão da razão moderna. Na nova sociedade programada, esse objeto compartilhado desaparecia, sinal suplementar da ausência de correspondência entre o sujeito e o sistema. Daí por que, diz Touraine, o objeto do conflito é o eu: a capacidade de um sujeito pes174 soal de existir enquanto sujeito.

\section{Abandono (parcial) de uma sociologia dos movimentos}

Enquanto Touraine reinvestia o campo teórico, o Cadis - laboratório que ele fundou em 1981 para investigar os novos movimentos sociais e que dirigiu até 1993 diversificou consideravelmente seu campo de preocupações para procurar responder a problemas da atualidade francesa: racismo, periferias urbanas e imigração, violência, escola, saúde, diversidade cultural. ${ }^{6}$ As técnicas de pesquisa da intervenção sociológica, inicialmente concebidas para interrogar movimentos sociais, foram adaptadas ao estudo desses novos objetos. François Dubet (1994) também formulou, naquele momento, sua sociologia da experiência, categoria de análise mais adaptada a esses novos objetos que

\footnotetext{
${ }^{6}$ Ver, no site do Cadis, as pesquisas dirigidas nesse período principalmente por Michel Wieviorka e François Dubet: http://cadis.ehess.fr/index.php?1902.
} 
a categoria ação. A bem dizer, estudava-se uma sociedade em decomposição e o termo mutação foi abundantemente mobilizado para descrever a face sombria da mudança, não obstante seu significado outro no contexto do acionalismo tourainiano (Touraine, 1973). ${ }^{7}$ Desde os anos 1990, por outro lado, o estudo da ação coletiva tornou-se um objeto preponderantemente abordado por pesquisadores da área de ciência política ou desenvolveu-se fora do Cadis. ${ }^{8}$

Três exceções a esse quadro geral são os estudos de Castelain-Meunier (1992, 2005) sobre os homens, a paternidade e a incidência do movimento feminista e do movimento gay sobre eles. Embora essas pesquisas se inscrevam em um registro empírico de investigações sobre as relações de gênero e suas transformações, elas podem, sem dificuldade, ser associadas a uma dinâmica de movimentos culturais. Touraine jamais se preocupou em formalizar a noção de movimentos culturais, contrariamente ao que havia feito com a de movimentos sociais. Mas é indiscutível que os objetos abordados por Castelain-Meunier no âmbito do Cadis são os que melhor correspondem a essa noção, que remete a mudanças nas práticas privadas, as quais, por efeito de agregação, convertem-se em mudanças nas representações e nas práticas coletivas. Do mesmo modo, a questão do sujeito pessoal esteve muito presente nos estudos de Bataille (2003) sobre os pacientes portadores de câncer. A partir de meados dos anos 2000, as pesquisas de Pleyers miraram decididamente nas mobilizações globais, de início com estudos sobre os Fóruns Sociais Mundiais (Pleyers, 2011) e, mais

\footnotetext{
7 Idem.

${ }^{8}$ Exemplo significativo são as lutas em torno da epidemia da aids, recentemente imortalizadas no filme multipremiado Cento e vinte batimentos por minuto, de Robin Campillo. Registram-se vários estudos sobre o assunto, desenvolvidos por cientistas políticos ou sociólogos de fora do Cadis. Apenas a título de exemplo e sem pretensões a um registro exaustivo, Favre (1992), Barbot (2002) e Buton (2005). A pesquisa de Jeanine Barbot foi dirigida por Claudine Herzlich no Centre d'Etude des Mouvements Sociaux (Cems), laboratório que Touraine dirigiu antes de fundar o Cadis.
} 
recentemente, através da reunião de pesquisas sobre uma ampla gama de ações coletivas que adquiriram importância em escala local, ao mesmo tempo em que participavam de protestos de escala global (Bringel e Pleyers, 2017).

Touraine, por sua vez, deixou de lado a sociologia empírica, e mesmo teórica, apoiando cada vez mais sua reflexão na história das ideias - a ponto de convidar seus leitores, em um livro de 2013, a abandonar a disciplina e a substituí-la por uma ciência moral reinventada (Touraine, 2013). Nesse novo registro de expressão, dois temas principais acompanharam uma longa lista de publicações: a ideia do fim das sociedades e do fim do social; e a intuição de que a mulher seria, na contemporaneidade, a nova figura cultural do sujeito.

Desde 1981, pelo menos, Touraine vem chamando a atenção para o fato de que a sociologia ter-se-ia libertado de um objeto dela constitutivo em sua origem, o estudo da sociedade. Muitos sociólogos ter-se-iam insurgido contra 176 essa definição da disciplina, que marcou profundamente a sociologia clássica, eliminando por completo de suas análises qualquer referência à ideia de sociedade. No melhor dos casos, a sociedade tornara-se, para alguns deles, um efeito não intencional, derivado da agregação de ações individuais. Essa recusa da ideia de sociedade traduziu-se em seguida em vários outros livros. Em 1995, Touraine interrogou-se sobre nossa capacidade de viver juntos, não obstante o fato de sermos ao mesmo tempo iguais e diferentes. A expressão "viver juntos" era proposta como um substitutivo ao termo banido "sociedade". Em 2013, um novo livro insistiu nessa temática, propondo a ideia não apenas do fim da sociedade, mas mais ainda do fim do social. ${ }^{9}$

\footnotetext{
9 Em carta dirigida a Touraine em 2013, comentando seu livro (e sobre a qual conversamos em encontro posterior), manifestei meu completo acordo quanto à ideia de um fim das sociedades, mas também meu completo desacordo quanto à ideia de fim do "social", mediação socioeconômica através da qual um poder global continua a se exercer sob diversas formas.
} 
O segundo tema, o da centralidade da mulher como nova figura cultural do sujeito, atravessou pelo menos três livros (Touraine, 2005, 2006, 2007). Ali, a experiência feminina era pensada através de seu impacto sobre o modo de funcionamento de um mundo antes marcado pela especialização e pela separação entre vida pública e privada; e doravante caracterizado por esse elemento primordial na experiência feminina - o desejo, o esforço e a capacidade para combinar essas duas dimensões da experiência social.

Em seus dois últimos livros $(2015,2016)$, Touraine registra a importância de novos atores coletivos que emergem em um cenário globalizado. Na sociedade de comunicação (o termo banido - sociedade - retorna freqüentemente, embora sem a importância conceitual que lhe foi atribuída pela sociologia em sua origem), faríamos face a um poder total, ao mesmo tempo econômico, político e cultural. Os novos movimentos que vemos emergir seriam pautados por um apelo à democracia e à dignidade humana, princípios mais do que tudo de natureza ética. Para Touraine, esses movimentos participam de uma afirmação dos direitos fundamentais dos seres humanos enquanto sujeitos (pessoais), capazes de se construir e de se transformar, transformando ao mesmo tempo seu ambiente social e natural. A ação coletiva na sociedade de comunicação, diz ele também, não manifesta apenas, nem principalmente, as contradições internas de uma dominação econômica e política; manifesta sobretudo um modo histórico de afirmação de direitos e da legitimidade social e política daquilo que não é mais um conjunto de reivindicações, mas um movimento de libertação do sujeito humano.

\section{Um legado do acionalismo tourainiano?}

Ao abandonar a sociologia, Touraine de certo modo deixou órfãos aqueles que o cercavam. Órfãos daquilo que por longo tempo caracterizou seu trabalho de sociólogo: a 
vontade de integrar estreitamente pesquisa empírica e teoria social. Ao sugerir, como em 2013, que uma ciência moral reinventada substituísse a sociologia, apenas explicitou as bases analíticas em que ele próprio passou a mover-se, no terreno das ideias - seu lugar de fala, como se costuma dizer hoje. O caminho para ele é sem volta. E para nós?

Nas condições históricas em que esse abandono se efetuou - e Touraine repetiu isso inúmeras vezes - o mais visível, no plano empírico, era, no seu vocabulário, a separação entre o sujeito e o sistema. Concretamente, isso significava uma dinâmica econômica socialmente desenraizada, comandada pelo capital financeiro; e, paralelamente, a emergência de uma onda identitária - no caso da França e da Europa, parte ancorada em imigrantes pobres, desempregados, e nas suas práticas religiosas, e parte em franceses "brancos" ("petits blancs", conforme a expressão consagrada) em situação de mobilidade social descendente, simpatizan178 tes potenciais de uma extrema-direita nacionalista e xenófoba. O registro empírico mais amplo dessa separação foi provavelmente aquele efetuado por Castells em sua trilogia sobre a Era da Informação $(1996,1997,1999)$ e, mais particularmente, no segundo volume, justamente intitulado $O$ poder da identidade.

Isso era, de fato, o mais visível e traduziu-se no debate francês através da preeminência do tema da exclusão, que colonizou o que de mais significativo se fez no período em matéria de sociologia urbana. No plano do menos visível, registram-se as pesquisas pioneiras de Alain Tarrius que, pelo menos desde 1987, vão revelar uma outra face dessas populações de excluídos - sua capacidade em utilizar a mobilidade entre as duas margens do Mediterrâneo como recurso para inscrever-se em uma economia global. Esta última, embora informal e dita "subterrânea", desenvolvia-se a céu aberto, tendo como plataforma de interligação de redes territoriais e humanas um bairro do centro de Marseille, Belsunce. 
Essas práticas de participação dependente dos migrantes na economia global configuraram aquilo que, em um amplo leque de pesquisas - primeiro na esteira de Alejandro Portes (1997, 1999), que analisou a circulação de migrantes entre os Estados Unidos e a região caribenha, e depois do próprio Tarrius (2002) - designou-se como um fenômeno de "globalização por baixo". ${ }^{10}$

No abandonado vocabulário do acionalismo tourainiano, essas práticas poderiam ser qualificadas como estratégicas, de nível mais baixo portanto que os movimentos sociais a que Touraine originalmente atribuiu papel tão central; e não obstante capazes de extrair uma população de excluídos de suas situações de exclusão, inscrevendo-a em dinâmicas de mobilidade territorial e social, abrindo caminho para que se construíssem como sujeitos de suas próprias vidas, sem necessitar refugiar-se em atitudes de corte sectário como as descritas por Castells (1997). Não que essas lógicas sectárias não existissem. Não apenas existiam, mas continuam existindo e drenando muita energia das periferias urbanas francesas, como mostram há vários anos os estudos de Khosrokhavar $(2013,2017)$ sobre a radicalização religiosa. Mas elas não eram toda a realidade. Para além delas, havia também condutas positivas e de mobilidade social, embora com repercussões do ponto de vista da implosão dos quadros institucionais-legais - notadamente toda a esfera do direito do trabalho, sobre os quais se assentaram as democracias modernas. Participavam portanto, à sua maneira, de um processo que Touraine dizia ter conduzido ao "fim das sociedades", mas apoiando ao mesmo tempo sobre si próprios as condições através das quais construíam suas vidas e se construíam enquanto sujeitos (Peralva, 2015, 2016).

${ }^{10}$ No Brasil, Ribeiro (2006, 2007) utilizou os termos “outras globalizações" e "globalização popular”. Para um balanço da literatura, conferir Peralva (2015). 
Mais recentemente, a série de movimentos que emergiram no Brasil na esteira de 2013 convidam a nos interrogarmos sobre a pertinência do uso do aparelho conceitual tourainiano para analisá-los, ao mesmo tempo que sobre os limites de seu legado. Três fenômenos importantes parecem ter-se delineado no âmbito do movimento de 2013. Em primeiro lugar, um conjunto de lutas urbanas, em parte (mas não apenas) induzidas pela proximidade de dois mega-eventos esportivos (a Copa do Mundo de 2014, precedida em 2013 pela Copa das Confederações; e os Jogos Olímpicos de 2016). Contestaram-se naquele momento uma série de políticas de promoção inconsiderada dos interesses das empresas de transporte urbano, das empreiteiras e da Fifa, sem que se levasse em conta o ponto de vista dos cidadãos sobre a vida na cidade. Em segundo lugar, 2013 introduziu no cenário brasileiro um fenômeno novo de comunicação, apoiado nas redes sociais, que alterou duravelmente as condições em que se produz e se consome informação no país, rompendo o monopólio de fala da grande imprensa. E, enfim, terceiro elemento, 2013 pôs em cena coletivos de ativistas em ruptura com o quadro político-partidário brasileiro - coletivos de sensibilidade autonomista e libertária, que implementaram uma renovação considerável das práticas militantes e das formas de organização da luta com inspiração e orientação democráticas. ${ }^{11}$

No plano das lutas urbanas, 2013 deu visibilidade a um importante conflito de orientações do ponto de vista do direito à cidade e da gestão da cidade. Mobilidade, moradia e planejamento urbano foram pautas fundamentais. O projeto Tarifa Zero, que remonta à gestão de Luiza Erundina na Prefeitura de São Paulo (1989-1992), foi referência em várias

\footnotetext{
11 Na esteira de 2013, também foram gerados, em meio aos escombros do sistema político-partidário, um conjunto de movimentos de sensibilidade liberal, como o MBL ou o Vem pra Rua, que não serão analisados aqui. As considerações sobre 2013 baseiam-se em uma pesquisa da autora (Peralva et al., 2017), utilizada aqui para ilustrar a maneira como o acionalismo tourainiano poderia ser remobilizado em favor de uma compreensão daqueles acontecimentos.
} 
lutas contra o aumento das tarifas dos transportes desde o começo do século, antes de tornar-se, a partir de 2005, um objetivo do Movimento Passe Livre (MPL), criado no Fórum Social Mundial de Porto Alegre. O projeto, como se sabe, propõe a criação de um Fundo de Transporte que financiaria a mobilidade urbana, democratizando seu acesso para o conjunto dos usuários, independentemente de suas condições individuais de renda. A questão da moradia popular vem sendo objeto de uma luta contínua do Movimento dos Trabalhadores Sem Teto (MTST) há mais de 20 anos, mas ela foi novamente pautada em 2013 no contexto da resistência às remoções ligadas à preparação da Copa do Mundo e dos Jogos Olímpicos. A Articulação Nacional dos Comitês Populares da Copa (Ancop) e os comitês locais formados nas 12 cidades-sede tiveram papel primordial nessa resistência.

Alguns polos de conflito foram particularmente emblemáticos. Na Vila Autódromo - aglomeração precária de moradias, beneficiária de uma concessão de terreno feita pelo governo do estado do Rio de Janeiro, e situada em área onde a Prefeitura construiu o Parque Olímpico - um contra-projeto de renovação urbana, elaborado por moradores e urbanistas e parcialmente vitorioso, disputou espaço com o projeto oficial (Bayer, 2017). O conflito incidia diretamente sobre as lógicas elitistas do planejamento urbano, pilotadas por políticos e empreiteiras e visando excluir da área populações de baixa renda. O movimento \#OcupeEstelita se opôs e obteve na Justiça o embargo à construção de um conjunto de torres no espaço do antigo parque ferroviário Estelita, patrimônio urbanístico do centro de Recife (Nogueira, 2015). ${ }^{12}$ O movimento \#Ocupacocó, em Fortaleza, opôs uma resistência de quatro meses à destruição de uma área verde para a

12 O vídeo Cabeça de Prédio, publicado em dezembro de 2015 na página do Movimento \#OcupeEstelita no Facebook, é de grande interesse na medida em que traduz em imagens da cidade os termos de um conflito em torno das lógicas da urbanização. 
construção de um viaduto, em uma cidade que havia perdido, em 35 anos, $90 \%$ da sua cobertura vegetal (Pinheiro, 2014). Lutas semelhantes foram registradas de norte a sul do país, marcadas por uma aliança constante entre movimentos populares e diversos profissionais de classe média. Modelo muito presente nas análises de Touraine sobre a consciência operária, que ele jamais reduziu à pura resistência dos proletários, arguindo que dos operários qualificados vinha a capacidade, no interior do movimento, de projetar a luta em um conflito de orientações em torno da historicidade. Historicidade por sua vez percebida como programa de investimento econômico e definição cultural do desenvolvimento.

Conforme dissemos, 2013 também alterou em profundidade e duravelmente as condições de produção e circulação da informação no país. Houve uma ruptura do monopólio da fala das grandes empresas de comunicação. Ainda que um novo quadro institucional não tenha acompa182 nhado e regulado essa mudança, e ainda que certas dimensões negativas do fenômeno, como a circulação acelerada de fake news nas redes sociais, venham chamando a atenção de pesquisadores e estejam na origem da formação de coletivos de checagem entre os profissionais da imprensa, tudo não é negativo nessa mudança. Suas dimensões positivas são mesmo consideráveis. Uma vasta gama de coletivos de comunicadores de favelas - Ocupa Alemão, Ocupa Borel, Coletivo Papo Reto, Maré Vive e muitos outros - disseminaram-se no Rio de Janeiro, mobilizando-se principalmente em torno daquilo que Silva (2015) chama de "terceira geração" de demandas e direitos. ${ }^{13}$ Thâmara (2014) relembra o quanto,

\footnotetext{
13 As demandas de primeira geração, diz ela, teriam como eixo a busca de acesso a serviços materiais básicos - água, energia, pavimentação, telefonia pública e equipamentos de educação e saúde. As de segunda geração envolveriam o acesso a serviços mais sofisticados - ensino superior, formação em línguas estrangeiras, informática, como via de acesso a empregos qualificados. As demandas de terceira geração envolveriam questões vinculadas ao gênero, à etnia, à orientação sexual, à segurança, ao meio ambiente e aos direitos humanos lato sensu (Silva, 2015, p. 26).
} 
nesse novo contexto, a campanha \#CadêoAmarildo, pilotada pela Anistia Internacional, foi importante para fazer com que convergissem a indignação da opinião pública diante de ações policiais violentas empreendidas contra manifestantes e a indignação contra o massacre desse pedreiro pobre da favela da Rocinha pela mesma polícia, que agia de forma ainda mais violenta em um contexto definido pela presença de populações matáveis, conforme o termo preciso de Agamben (1997). A esses coletivos somaram-se outros, formados por universitários e profissionais de classe média, que através de vídeos e fotografias propunham uma tradução emocional e estética das mobilizações. E, mais ainda, coletivos de midialivristas stricto sensu, formados por produtores não profissionais de informação, dos quais uma parte mantém relações complexas e ambivalentes com o jornalismo profissional: aspirantes a jornalistas vindos das favelas de São Paulo, em situação de mobilidade social, estudantes de comunicação de grandes universidades públicas e privadas, jornalistas recém-formados em universidades de segundo time - todo esse universo converge em uma nebulosa de coletivos, que tenta dar resposta à crise da imprensa profissional. Crise que teve como um de seus indicadores as demissões maciças de jornalistas nas redações de São Paulo, em junho de 2013, conforme registrou Bruno Torturra em artigo de dezembro daquele ano para a revista Piauí (Torturra, 2013).

Peralva et al. (2017a, 2017b) chamaram a atenção para as relações ambíguas entre ativistas e jornalistas profissionais que doravante parecem caracterizar esse novo campo da comunicação. As lógicas de experimentação de novas tecnologias e as novas modalidades de produção da informação, em parte apoiadas no streaming que garante filmagens ao vivo com recursos limitados e qualidade ainda precária; ou no crowdsourcing que garante amplitude no levantamento de informações, simplesmente graças a redes militantes - tudo isso tem um impacto sobre o trabalho dos jornalistas, que se 
perguntam como fazer a diferença no quotidiano para justificar a pertinência do seu campo profissional. Observa-se mesmo um mimetismo entre órgãos da grande imprensa que experimentam técnicas de produção e difusão da informação, como as entrevistas em streaming nas redes sociais ou as filmagens com smartphones adotadas pela Rede Globo. Por outro lado, a ausência de um modelo econômico capaz de garantir a reconfiguração e a estabilização desse novo campo da comunicação parece levar muitos aspirantes a jornalistas a uma participação dependente na imprensa profissional, que lhes assegura visibilidade, mas em condições que incidem sobre a precarização da atividade jornalística e a aprofundam.

Todas essas mudanças são fundamentais do ponto de vista da prefiguração de uma nova institucionalidade democrática no plano da comunicação, a ser negociada no futuro, do mesmo modo que o são também, no plano político, 184 aquelas que se efetuaram no nível das práticas militantes e organizacionais. $\mathrm{O}$ ano de 2013 engendrou uma nebulosa de pequenos coletivos de ativistas - e não apenas de midiativistas - auto-geridos, reivindicando sua independência em relação aos partidos políticos e às grandes organizações sindicais e populares, cujas relações com o PT eram geralmente estreitas. ${ }^{14}$ No interior dessa nebulosa, comunidades e redes de extensão nacional, estabilizadas por uma longa história no campo da cultura, como o Fora do Eixo, mas também formas de organização menos estáveis como rodas de conversa, múltiplas assembleias populares instaladas em diferentes cidades do país, e ocupações de espaços públicos (praças, parques, terrenos em disputa). A articulação desses diferentes coletivos caracterizou-se por relações de horizontalidade e construiu-se no interior do movimento, com

\footnotetext{
14 A participação do MTST, nesse universo, talvez tenha sido a exceção que confirma a regra.
} 
instrumentos próprios e formas de expressão artística, às vezes pautadas pela reapropriação de recursos e lógicas da publicidade comercial, com vídeos projetados nas paredes das cidades relembrando as pautas da luta, como no caso do coletivo Projetação. Nada disso era propriamente novo, posto que correspondia a tendências gerais que já se haviam observado na segunda onda do movimento global (Castells, 2013). ${ }^{15}$ De resto, a segunda onda brasileira manteve laços estreitos com a primeira - por um lado, através do caráter global dos dois mega-eventos esportivos que catalisaram os protestos de 2013, institucionalizado através da chamada Lei da Copa e pela presença no país, naquele momento, de uma imprensa internacional que contribuiu para dar-lhes visibilidade; mas também, por outro lado, pela presença explicitamente reconhecida, no interior do movimento, de uma herança de lutas da geração do começo do século e pelas novas redes de solidariedade, colaboração e troca de experiência nas quais os coletivos de 2013 viram-se inseridos.

\section{Contribuições e limites da sociologia de Alain Touraine para a análise e compreensão de movimentos como o de 2013 no Brasil}

Em que medida o acionalismo tourainiano pode ser mobilizado para entender o movimento de 2013, e outros de mesmo tipo? Já nos referimos à questão de um conflito, patente nas lutas daquele ano, em torno das grandes orientações do desenvolvimento urbano. Lutas, portanto, que não apenas continham demandas - oposição às expulsões, moradia popular - mas que disputavam o sentido do que deveria ser feito do ponto de vista do viver na cidade. Várias outras lutas - as do Movimento dos Trabalhadores Rurais

\footnotetext{
${ }^{15} \mathrm{O}$ movimento anti-globalização do início do século visou os grandes órgãos estruturadores do poder global. A segunda onda, filha da web 2.0, interpelou a democracia e seus limites a partir de diferentes realidades nacionais (Peralva et al., 2017a, 2017b; Bringel, 2017).
} 
Sem Terra (MST) contra o agronegócio e por uma agricultura sem agrotóxicos, as dos expulsos por barragens pela defesa do meio-ambiente - podem ser compreendidas na mesma perspectiva. Os padrões culturais do desenvolvimento econômico estão sendo disputados palmo a palmo, e isso corresponde no acionalismo tourainiano aos conflitos mais importantes, os conflitos de historicidade.

Por outro lado, o conjunto de grandes movimentos que emergiram em escala mundial desde o início do século - a primeira e a segunda ondas da luta global, das quais 2013 faz parte - não podem ser qualificados senão como movimentos democráticos. Eles o são, não apenas enquanto manifestação de demandas de abertura do sistema político, como em parte ocorreu na Primavera Árabe. Mas também, mais profundamente, enquanto conflitos em torno de uma repartição menos assimétrica e menos brutal do poder sobre o desenvolvimento, como manifestam os exemplos 186 que indicamos acima. E o são, por fim, enquanto escolhas organizacionais de tipo horizontal, por oposição ao sistema de partidos e aos regimes representativos que configuram sistemas verticalizados.

Touraine sempre foi sensível à questão da democracia. A ela dedicou um livro (Touraine, 1994), embora por ele próprio considerado como uma obra menor. Ao expor os resultados de suas pesquisas sobre o sindicato polonês Solidariedade, considerou-o como o mais importante movimento social da segunda metade do século XX e como um movimento social "total", por combinar uma tripla dimensão sindical, nacional e democrática. Em Production de la société (Touraine, 1994), preocupou-se em distinguir a noção de contradição, motor segundo ele de movimentos históricos e rupturas revolucionárias, e os conflitos internos a uma sociedade nos quais se ancoravam condutas de historicidade, implicando renegociações e reorientações em torno de certos objetos - ou do que estava em jogo na 
historicidade (l'enjeu de l'historicitê). O conflito operário, por exemplo, estruturaria um movimento social que se distinguiria da guerra por não visar a destruição de seu adversário e por compartilhar com ele uma representação comum do mundo (o progresso humano, embora dele os adversários em conflito propusessem definições distintas).

Isto posto, e curiosamente, Touraine jamais se deteve, mesmo em seu percurso teórico mais recente - aquele que o lançou no campo da história das ideias - em qualquer discussão relativa às formas políticas de exercício da democracia, ou à crise do regime representativo. Jamais se debruçou sobre temáticas próprias da sociologia política strictu sensu. No meu entender, por isso mesmo é difícil encontrar diretamente na sociologia tourainiana elementos capazes de articular o sentido dos movimentos globais de segunda geração com a crise da democracia e sua renovação necessária, elementos fortemente presentes nesses movimentos.

As características democráticas dos movimentos da segunda onda requerem vários níveis de análise. Primeiramente, são expressão de uma dinâmica social democrática que se traduziu, no espaço brasileiro (mas também mundial), em elevação significativa no meio popular dos patamares de educação, de acesso à informação e de acesso à cultura, não obstante graus persistentes e importantes de desigualdade social. A educação, a informação e a cultura tornaram-se recursos de luta política mobilizados por populações pobres, independentemente ou em aliança com segmentos de classe média. Em segundo lugar, generaliza-se a forma rede, horizontal e colaborativa por definição. Redes que estruturam o poder econômico em escala global, mas que estruturam também o ativismo de uma nebulosa de coletivos presentes nesses movimentos. Essa estruturação é favorecida por uma base tecnológica de acesso simples, com características de interatividade, a web 2.0. No 2013 brasileiro, o Facebook foi uma rede social fundamental. A tudo 
isso se acresce, por outro lado, uma crise profunda, particularmente intensa no caso brasileiro, que afeta os partidos e os regimes representativos.

A era da democracia dos partidos, diz Manin (2012), ficou para trás. A unidade que os ligou por um tempo às suas bases, fenômeno que marcou pelo menos a experiência europeia no contexto das sociedades industriais, foi rompida com a emergência de coletividades humanas altamente individualizadas, tanto do ponto de vista de suas formas de inscrição no mundo do trabalho, quanto de suas formas de consumo, ou ainda do modo como constroem suas relações entre o permitido e o proibido - aquilo que Lipovetsky (1992) chamou, já no título de seu livro, de "a ética indolor dos novos tempos democráticos”. Manin contesta a ideia de uma crise dos regimes representativos e eletivos, optando pela hipótese de uma mutação. Sugere que os partidos perderam efetivamente as características do passado, sem ter no entanto desaparecido posto que continuam, em um novo contexto, cumprindo as funções de operadores do sistema eleitoral. Funções, no entanto, que se exercem com novo formato: o das democracias "do público" ou da "opinião pública", onde partidos de baixa densidade representativa, apoiados em institutos de pesquisa, contribuem para eleger figuras carismáticas e midiáticas, que usam esses mesmos partidos para fins eleitorais, porém mantendo grande margem de autonomia em relação a eles (Manin, 2012, pp. 291300; pp. 313-314).

Em resposta aos problemas advindos dessa crise - ou dessa mutação - observa-se a emergência de movimentos insurgentes de novo tipo (Brancaleone, 2015), de movimentos de base comunitária e corte autonomista, ou ainda apoiados em uma ampla sensibilidade libertária, que remetem a formas deliberativas de exercício da democracia. Esses movimentos fabricam não uma nova institucionalidade, mas novas práticas. Paralelamente, em escala não menos 
significativa, experimentos deliberativos semi-institucionais disseminam-se através do planeta, reatando com formas pré-representativas de exercício da democracia que prevaleceram ao longo da história (Sintomer, 2011).

$\mathrm{O}$ interesse dessas formas deliberativas de exercício da democracia, a meu ver, é que elas são potencialmente capazes de fundar uma nova definição do "comum", capaz de substituir aquela que vigorou no quadro de relações de trabalho e dos conflitos de classes que acompanharam a formação do movimento operário. O confronto de ideias nesses espaços, indica Sintomer (2011), produz uma opinião qualificada, muito diferente da opinião pública intuitiva e instável característica dos regimes representativos. Nesses experimentos, o "comum" pressupõe o reconhecimento da legitimidade das deliberações adotadas através da discussão coletiva, independentemente das divergências entre as partes, que de resto se reduzem ao longo do processo. Há aí talvez uma arquitetura institucional suscetível de permitir tratamento continuado, e mais eficaz, dos grandes conflitos de orientação em jogo na historicidade. A natureza democrática dos espaços deliberativos reconfigura as condições de organização da vida coletiva, em condições de horizontalidade que contrastam com a lógica vertical e hierárquica própria dos regimes representativos.

O alto grau de individualização de nossas sociedades não me parece ser um obstáculo à reinvenção desse novo comum. O movimento operário surge, nas representações do século XX, como uma categoria imediatamente coletiva. Touraine, no entanto, em seus estudos sobre a consciência operária, sugeriu que por trás dessa categoria coletiva existia um sujeito individual. Se admitirmos a pertinência dessa hipótese, como, então, esse sujeito individual transformou-se em categoria coletiva? Várias elementos, provavelmente, explicam tal processo. O primeiro é a existência de uma experiência compartilhada. $\mathrm{O}$ segundo, certamente, o caráter performativo dos conflitos, dos debates e das representações que vão 
construindo, ao longo do século XIX, em uma Europa em vias de industrialização, a figura da classe operária e do movimento operário. Figuras que, até não muito tempo atrás, no continente europeu, ocuparam um lugar central na estruturação de um imaginário da democracia.

De diversas maneiras a dinâmica histórica, que tornou obsoleto o conflito operário nos termos em que ele se construiu no passado, incidiu também sobre a representação do comum, duplamente associada ao movimento operário e à nação como coletividade imaginada. Ao fazer isso, afetou também, muito diretamente, as condições de funcionamento da democracia, gerando um desequilíbrio brutal das relações de poder. É desse ponto de vista, a meu ver, que a reconfiguração dos espaços institucionais e dos espaços de deliberação coloca-se com urgência extrema. Há algo a reinventar neste momento, em condições tão difíceis ou talvez mais difíceis do que as que se colocaram para um país como 190 a França ao fim do século XIX, no momento da instauração da Terceira República e daquilo que Donzelot (1984) designou como "a invenção do social". O "social", como Touraine vem repetindo há vários anos, já não consegue mais ser aquilo que dá liga ao "comum". Tudo indica que essa liga terá de vir diretamente de uma instância política - ao que tudo indica, de espaços reconfigurados de deliberação.

Nesse sentido, a reinstitucionalização da democracia, tal como prefigurada por movimentos sociais e experimentos das mais diversas naturezas, pelo simples fato de romper com os princípios desacreditados da representação, pode participar de uma reconfiguração do imaginário político e de um reencantamento da política enquanto tal. Essa hipótese implicaria necessariamente uma descentralização radical dos espaços de gestão e poder, que no entanto não seriam necessariamente geradores de localismos irredutíveis, desde que compativeis com mecanismos mais gerais de solidariedade coletiva. A dificuldade hoje não é a de imaginar uma nova 
arquitetura institucional em tais bases, mas a de alcançar esse redesenho em condições extremas de assimetria das relações de poder, tais como aquelas com que hoje nos deparamos.

\section{Angelina Peralva}

é socióloga, ex-professora da Faculdade de Educação da Universidade de São Paulo (FE/USP), professora emérita de sociologia da Universidade de Toulouse 2 e pesquisadora do Laboratoire Interdisciplinaire Solidarités, Sociétés, Territoires (LISST). Também é pesquisadora associada ao Centre d'Analyse et d'Intervention Sociologiques (Cadis), laboratório fundado por Alain Touraine na École des Hautes Études en Sciences Sociales, em Paris.

\section{Bibliografia}

AGAMBEN, Giorgio. 1997. Homo Sacer: le pouvoir souverain et la vie nue. Paris: Seuil.

BARBOT, Janine. 2002. Les malades en mouvements: la médecine et la science à l'épreuve du sida. Paris: Balland.

BATAILLE, Philippe. 2003. Un cancer et la vie: les malades face à la maladie. Paris: Balland.

BAYER, Mats. 2017. Méga-événements sportifs et politiques urbaines: le conflit de Vila Autódromo et les Jeux Olympiques à Rio de Janeiro. Mémoire de Master, $2^{\text {ème }}$ année, mention Civilisations, Cultures et Sociétés, parcours Espaces, Sociétés, Cultures dans les Amériques, IPEAT. Toulouse: Université de Toulouse 2.

BOUDON, Raymond. 1977. Effets pervers et ordre social. Paris: PUF. BOUDON, Raymond. 1979. La logique du social. Paris: Hachette.

BRANCALEONE, Cassio. 2015. Teoria social, democracia e autonomia: uma interpretação da experiência de autogoverno zapatista. Rio de Janeiro: Azougue Editorial.

BRINGEL, Breno. 2017. Movimientos sociales y la nueva geopolítica de la indignación global. In: BRINGEL, Breno; PLEYERS, Geoffrey (org.). Protesta e indignación global: los movimientos sociales en el nuevo orden mundial. Buenos Aires: CLACSO.

BRINGEL, Breno; PLEYERS, Geoffrey (org.). 2017. Protesta e indignación global: los movimientos sociales en el nuevo orden mundial. Buenos Aires: CLACSO. 
BUTON, François. 2005. Sida et politique: saisir les formes de la lutte. Revue Française de Science Politique, v. 5, n. 5, pp. 787-810.

CASTELAIN-MEUNIER, Christine. 1992. Cramponnez-vous, les pères! Les hommes face à leur femme et à leurs enfants. Paris: Albin Michel.

CASTELAIN-MEUNIER, Christine. 2005. Les métamorphoses du masculin. Paris: PUF.

CASTELLS, Manuel. 1996. A sociedade em rede. São Paulo: Paz e Terra.

CASTELLS, Manuel. 1997. O poder da identidade. São Paulo: Paz e Terra.

CASTELLS, Manuel. 1999. Fim de milênio. São Paulo: Paz e Terra.

CASTELLS, Manuel. 2013. Redes de indignação e esperança: movimentos sociais na era da internet. Rio de Janeiro: Zahar.

CROZIER, Michel; FRIEDBERG, Erhard. 1977. L'acteur et le système. Paris: Seuil.

DONZELOT, Jacques. 1984. L’invention du social: essai sur le déclin des passions politiques. Paris: Fayard.

DUBET, François. 1994. Sociologie de l'expérience. Paris: Seuil.

FAVRE, Pierre. 1992. Sida et politique, les premiers affrontements: 1981-1987. Paris: L'Harmattan.

KHOSROKHAVAR, Farhad. 2013. Radicalization in prison: the French case. Politics, Religion and Ideology, v. 14, n. 2, pp. 284-306.

KHOSROKHAVAR, Farhad. 2017. Nuevos perfiles yihadistas en Europa y radicalización en las cárceles francesas. In: BRINGEL, Breno; PLEYERS, Geoffrey (org.). Protesta e indignación global: los movimientos sociales en el nuevo orden mundial. Buenos Aires: CLACSO, pp. 167-173.

LINHART, Robert. 1978. LÉtabli. Paris: Minuit.

LIPOVETSKY, Gilles. 1992. Le crépuscule du devoir: l'éthique indolore des nouveaux temps démocratiques. Paris: Gallimard.

LYOTARD, Jean-François. 1979. La condition postmoderne. Paris: Minuit.

MANIN, Bernard. 2012. Principes du gouvernement représentatif. Paris: Flammarion.

MORAES, Vinicius de. 1959. O operário em construção. In: MORAES, Vinicius de. Novos poemas II. Rio de Janeiro: São José, pp. 45-51.

OLSON, Mancur. 1978. Logique de l'action collective. Paris: PUF.

PARSONS, Talcott. 1951. The learning of social-role expectations and the mechanisms of socialization of motivation. In: PARSONS, Talcott. The Social System. Glencoe, Illinois: The Free Press, pp. 201-248.

PERALVA, Angelina. 2015. Globalização por baixo e mercados ilegais. In: PERALVA, Angelina; TELLES, Vera da Silva (org.). Ilegalismos na globalização. migrações, trabalho, mercados. Rio de Janeiro: Editora da UFRJ. 
PERALVA, Angelina. 2016. Globalização, América Latina e os desafios para a democracia. Revista USP, n. 109, pp. 31-42.

PERALVA, Angelina et al. 2017a. O legado de 2013: coletivos de ativistas e a agenda política brasileira. Trabalho apresentado no $41^{\circ}$ Encontro Anual da Anpocs GT 8: Democracia e Desigualdade, Caxambu, 23 a 27 de outubro.

PERALVA, Angelina et al. 2017b. Resta algo de 2013? Liinc em Revista, v. 13, n. 2, pp. 381-400.

PLEYERS, Geoffrey. 2011. Alter-globalization: becoming actors in a global age. Cambridge: Polity Press.

PORTES, Alejandro. 1997. Globalization from below: the rise of transnational communities. Princeton: Princeton University. (Working Papers Series 98-01).

PORTES, Alejandro. 1999. La mondialisation par le bas: l'émergence des communautés transnationales. Actes de la Recherche en Sciences Sociales, n. 129, pp. 15-25.

RIBEIRO, Gustavo Lins. 2006. Other globalizations: alter-native transnational processes and agents. Rio de Janeiro: The Edelstein Center for Social Research. (Working Paper 4).

RIBEIRO, Gustavo Lins. 2007. El sistema mundial no hegemónico y la globalización popular. Série Antropologia, v. 410, pp. 7-23.

SILVA, Eliana Sousa. 2015. Testemunhos da Maré. Rio de Janeiro: Mórula Editorial.

SINTOMER, Yves. 2011. Petite histoire de l'expérimentation démocratique: tirage au sort et politique d'Athènes à nos jours. Paris: La Découverte.

TARRIUS, Alain. 1987. L'entrée dans la ville: migrations maghrébines et recomposition des tissus urbains à Tunis et à Marseille. Revue Européenne des Migrations Internationales, v. 3, n. 1-2, pp. 131-148.

TARRIUS, Alain. 2002. La mondialisation par le bas: les nouveaux nomades de l'économie souterraine. Paris: Balland.

THÂMARA, Thamyra. 2014. Junho preto: favelado ocupando as ruas. In: MORAES, Alana et al. (org.). Junho: potência das ruas e das redes. São Paulo: Friedrich Ebert Stiftung, pp. 158-175.

TORTURRA, Bruno. Olho da rua. Piaui, São Paulo, ano 7, n. 87, dez. 2013. Disponível em: https://piaui.folha.uol.com.br/materia/olho-darua. Acesso em: 15 fev. 2019.

TOURAINE, Alain. 1965. Sociologie de l'action. Paris: Seuil.

TOURAINE, Alain. 1966. La conscience ouvrière. Paris: Seuil.

TOURAINE, Alain. 1969. La société postindustrielle. Paris: Denoël.

TOURAINE, Alain. 1973. Production de la société. Paris: Seuil. 
TOURAINE, Alain. 1977. Un désir d'histoire. Paris: Stock.

TOURAINE, Alain. 1978. La voix et le regard. Paris: Seuil.

TOURAINE, Alain. 1981. Une sociologie sans société. Revue Française de

Sociologie, n. 22, pp. 3-13.

TOURAINE, Alain. 1987. Actores sociales y sistemas políticos en América Latina.

Santiago: PREALC.

TOURAINE, Alain. 1988. La parole et le sang. Paris: Odile Jacob.

TOURAINE, Alain. 1992. Critique de la modernité. Paris: Fayard.

TOURAINE, Alain. 1994. Qu'est-ce que la démocratie? Paris: Fayard.

TOURAINE, Alain. 1999. Comment sortir du libéralisme? Paris: Fayard.

TOURAINE, Alain. 2005. Un nouveau paradigme: pour comprendre le monde d'aujourd'hui. Paris: Fayard.

TOURAINE, Alain. 2006. Le monde des femmes. Paris: Fayard.

TOURAINE, Alain. 2007. Penser autrement. Paris: Fayard.

TOURAINE, Alain. 2013. La fin des sociétés. Paris: Seuil.

TOURAINE, Alain. 2015. Nous, sujets humains. Paris: Seuil.

TOURAINE, Alain. 2016. Le nouveau siècle politique. Paris: Seuil.

TOURAINE Alain et al. 1978. Lutte étudiante. Paris: Seuil.

TOURAINE, Alain et al. 1980. La prophetie anti-nucléaire. Paris: Seuil.

194 Paris: Seuil.

TOURAINE, Alain et al. 1981. Le pays contre l'Etat: luttes occitanes.

TOURAINE, Alain et al. 1982. Solidarité: analyse d'un mouvement social:

Pologne, 1980-1981. Paris: Fayard.

TOURAINE, Alain et al. 1984. Le mouvement ouvrier. Paris: Fayard. 


\section{CONFLITO E MOVIMENTOS SOCIAIS NO ACIONALISMO DE ALAIN TOURAINE}

\section{ANGELINA PERALVA}

Resumo: Este artigo discute as bases do acionalismo de Alain Touraine. Revisita o percurso teórico empreendido pelo autor, desde suas primeiras investigações sobre a consciência operária até um período mais recente, em que Touraine parece optar pelo abandono da sociologia em prol de uma ciência moral reinventada. Termina com uma interrogação sobre a pertinência e os limites de uma remobilização do aparelho sociológico tourainiano para analisar a segunda onda do movimento global. A partir da ideia de um conflito democrático que caracterizaria esse movimento, indica os aportes e os limites da sociologia tourainiana para responder a esse desafio.

Palavras-chave: Acionalismo; Historicidade; Conflito; Movimentos Sociais; Movimentos Globais.

\section{CONFLICT AND SOCIAL MOVEMENTS IN THE ACTIONALISM OF ALAIN TOURAINE}

Abstract: This study discusses the theoretical grounds of Alain Touraine's actionalism. It revisits the theoretical course taken by the author from his first researches on the worker's consciousness in the 1950's to a more recent period, when Touraine intends to abandon sociology and move to a reinvented moral science. The study ends with a question on the pertinence and the limits of a remobilization of Touraine's sociological device to analyse the second wave of the global movement. From the idea of a democratic conflict that characterizes this movement, it indicates the contributions and limits of Touraine's sociology to respond to this challenge.

Keywords: Actionalism; Historicity; Conflict; Social Movements; Global Movements.

Recebido: 06/04/2018 Aprovado: 25/02/2019 